\title{
IMPLEMENTATION OF OPTIMUM CURRENCY AREA CRITERIA AND ITS VOLATILITY: CASE STUDY ASEAN-5+3
}

\author{
Dimas Bagus Wiranata Kusuma \\ Arief Dwi Putranto ${ }^{1}$
}

\begin{abstract}
This paper is aiming to elaborate the case of how exchange rate volatility (ERV), which is supposedly considered to form optimum currency area (OCA), can be reduced in order justify the feasibility of the OCA idea within ASEAN5 plus three. Interestingly, the results provide some evidences that the ASEAN5+3 are considered not really ready to form OCA. It corroborates the existing opinion that the different in economic structure and its policies over foreign environment are becoming some barriers and challenging area to synchronize in the following time. The positive impacts AS to ERV which are incurred in ASEAN5+3 economies indicate the existence of inappropriate condition to form OCA since there are no similar shocks across a monetary union's participating countries. Under such condition, it would foster the costs of forgoing the exchange rate as a shock absorbing mechanism. It deserves to argue that those observed countries still are resisting their existing regime since they are till believing that they begin to establish the system of monetary which are able to absorb any possible shocks in regards of their SIZE. In sum, the ASEAN5+3 countries are considered to fulfilling the requirement to form currency optimum area which are able to main their stable currency.
\end{abstract}

JEL: D81, E52, F15, F36

Key words: Optimum Currency Area, a Single Currency, Exchange Rate Volatility, Stability

1 Dimas Bagus Wiranata Kusuma (dimas economist@yahoo.com) and Arief Dwi Putranto, (ariefdepee@hotmail.com), are affiliated in Economics Kulliyyah of Economics and Management Sciences International Islamic University Malaysia 


\section{INTRODUCTION}

After the introduction of Euro on eleven countries of Europe eleven years ago, and the expanding trend of continuous Euro adoption by increasingly the influx numbers of countries. Subsequently, there have been lots of study made on whether the replication of Euro experience can be applied, particularly in ASEAN-5+3 area. This is especially crucial after the lesson of 1997/1998 Asian financial crises, where dollar dominant to be adopted as exchange rate regime envisaged was not desirable for the pursuit of financial stability. Namable options alternative come forward to counter this by exercising currency peg (either to a single currency or basket of currency), flexible exchange rate regime, or monetary union. Numerous efforts have been put in place, for example the Chiang Mai Initiative (CMI) which was announced by the ASEAN+3 finance ministers, convening in May 2000. The CMI were made to initially facilitate the exchange of consistent, timely data and information, and to establish a regional financing arrangements. The other approaches are taking place to strengthen the idea of integration is structuring The ASEAN Economic Community (AEC) and ASEAN Free Trade Area (AFTA). Both of them are basically pronounced to create a stable, prosperous, and competitive ASEAN economic region in which free flow of goods, services, investment, and skilled labor through simultaneously implementations progressive tariff cuts via the Common Effective Preferential Tariff (CEPT) scheme.

However, the existence of regional integration needs macroeconomic coordination among countries within region. Therefore, the purpose of regional integration is to promote greater and foster the expansion works to synchronize business cycles, and finally to mitigate such shocks by sharing the loss with a trading partner because both countries assuming hold claims on each other's output (Robert Mundel, 1973). The intensive coordination would affect in reducing to some extent of macroeconomic volatility brought about by factors such as exchange rate volatility (Frankel and Wei, 1993). The European Union (EU) is considered as successful model of economic integration, under which exchange rate uncertainty and misalignment is avoided and trade and investment among members are promoted substantially (Ariccia, 1999).

The issue of integration could not far away from the emergence of exchange rate stability (ERS) matter. In fact, ERS is seemly vital in any effort to ensure macroeconomic stability. Economic theory suggests that misalignments in the real exchange rate of nations, as well as their departure from long-run equilibrium rates, negatively affect economic growth. These conditions create relative price uncertainty, trigger increased adjustment costs and decrease the efficiency of resource allocation in domestic markets (Kemme \& Teng, 2000). Hence, any effort to stabilize exchange rates allows for the creation of a more conducive business environment and can potentially increase economic growth rates. 
Given the importance of the above issues in promoting prosperity among ASEAN nations, the question of how exchange rate volatility (ERV) can be reduced becomes vital. The regional financial crisis in 1997 to 1998 eroded the credibility of unilateral fixed exchange rates, and renewed calls for greater monetary integration and regional exchange rate stability in East Asia (EA). The success of the Euro also raised interest in the viability of a common currency for both ASEAN and the developed economies of East Asia (Zhang, Sato, \& McAleer, 2004). This issue was addressed extensively in the November 1999 ASEAN meeting, where the grouping's 10 members were urged to work harder to achieve the target of a common market and a single currency (Asia Now, November 29, 1999; Hurley \& Santos, 2001).

However, a formal institutional framework appears to be lacking in the drive to achieve monetary integration. In addition, economic and financial conditions differ greatly among the ASEAN nations. Nevertheless, it should be noted that the economies in ASEAN have experienced a rapid, seemingly spontaneous period of regional integration in the last decade. This integration arose as a result of the unilateral liberalization of the goods and capital markets.

Despite the fact that quantifying the costs and benefits and applying the guidelines of an optimum currency area (OCA) is difficult, the literature shows that ASEAN has several characteristics that suggest that the benefits of implementing a common currency may be significant, even relative to the costs (Madhur, 2002). Overall, the composite OCA indices for the region are similar to those for the EU (Bayoumi \& Eichengreen, 1998). These indices take into account intraregional trade, wage-price flexibility, labor mobility, and shock symmetry. By using a variety of such indicators from the OCA literature, Bayoumi and Eichengreen (1998) conclude that, from a purely economic perspective, ASEAN is as suitable for an OCA as Europe was prior to the Maastricht Treaty.

\begin{tabular}{|c|c|c|}
\hline \multicolumn{3}{|c|}{$\begin{array}{l}\text { Table IV.1. Economic Growth And Depreciation } \\
\text { Around The } 1997 \text { Economic Crisis }\end{array}$} \\
\hline \multicolumn{2}{|c|}{ Growth 1998 (\%) } & Depreciation (\%) \\
\hline Indonesia & -1.4 & 85 \\
\hline Malaysia & -6.5 & 45 \\
\hline Philippines & -0.5 & 40 \\
\hline Singapore & 1.5 & 20 \\
\hline Thailand & -8.0 & 60 \\
\hline China & +6 & 0 \\
\hline Japan & -2 & +8 \\
\hline South Korea & -6.8 & 29 \\
\hline
\end{tabular}


During the post-Bretton Woods period, the ASEAN-5+3 nations experienced substantial ERV despite adopting a crawling peg exchange rate regime. Between 1974 and 1999, the Indonesian Rupiah was the most volatile of the ASEAN currencies, followed by the Philippine Peso, while the Singapore Dollar was the least volatile (Hurley \& Santos, 2001). However, in the case of ASEAN5+3, China had experienced the least volatile countries since it has been implementing the peg regime over US dollar. Other evidence documenting the volatility of ASEAN currencies can be found in studies done by Nam and Mc Aleer (2002) and Lee and Tan (2004). From Table IV.1, generally ASEAN currencies appear to be too volatile and sensitive to sudden shocks. The order of volatility, however is in contrast to Hurley and Santos (2001). Despite this difference, it is apparent that the two countries most affected by problems of volatility, Thailand and Indonesia, also suffered the largest negative economic growth. China was indicated as the least volatile of the ASEAN-5+3 states, and was least affected by the economic crisis.

A popular view among economists and policy makers since the Asian crisis is that developing countries with open capital accounts have a bipolar solution to the exchange rate dilemma: either a free float or a hard peg. The hard peg solution refers specifically to the use of a common currency or the formation of a monetary union. Hochreiter and Winckler (1995) outlined the costs and benefits of giving up a national currency and joining a monetary union. Among the effects described in relation to the Euro was a boost in economic growth that occurred via increased trade (Rose, 2000; Frankel \& Rose, 2002). Joining a monetary union also facilitated greater microeconomic efficiency by eliminating ERV, hence lowering interest rates and promoting international use of the currency.

Given relative stability of Singapore's currency, we examine the bilateral exchange rate between the four major ASEAN economies plus three, namely Malaysia, Thailand, the Philippines and Indonesia, the Singapore Dollar, China, South Korea, and Japan. It is our intention in this paper to first find an explanation for the volatility in the exchange rate, and thus determine the feasibility of a single currency in ASEAN-5+3 region. By definition, if the OCA variables shown in this study significantly explain the variation in exchange rate, the ASEAN-5+3 common currency would be deemed viable and likely strengthen the argument for the AFTA. It is also our intention to examine if there is reverse (Granger) causality in the relationship; in other words, whether ERV had an impact on OCA criteria. Should the empirical model validate the formation of an OCA in ASEAN-5+3, our final motivation would be to identify the difficulties that ASEAN-5+3 nations have to face even before they start on the road towards a common currency.

The paper is organized as follows. The second section that follows presents a review of the existing literature, and includes definitions of the OCA variables. The third section specifies 
the empirical model along with its estimation procedures. This is followed by an empirical assessment of the model with the results being interpreted in the forth section. In addition, section fourth as part of the answer for the third objective, we raise the possible difficulty faced by ASEAN-5+3 in successfully forming a common currency and thus become the agenda for ASEAN $-5+3$ to work through before the aim of forming it can be realized. The paper concludes in section five by proposing some of safeguards and strategies that envisaged as keys to the success of the forming OCA.

\section{THEORY}

Seminal contribution by Mundell (1961) and McKinnon (1963) had risen to the theory of optimum currency area (OCA) as well as monetary and exchange rate cooperation among countries. Mundell (1963) had pointed out that countries which have symmetrically affected by shocks are the prime candidate and appropriate for an OCA. Subsequently, Mundell and Mc Kinnon through their research, found at least four benefits would impinge of adopting a common currency, namely :

1. Extent of trade happens if potential members of a union trade a lot with each other since its existence is expected would reduce transaction costs.

2. Nature of disturbances happens if the countries experience similar shocks so that the cost of giving up monetary policy independence would decrease.

3. Degree of labor mobility happens if high labor mobility across borders can be a useful mechanism for adjusting to asymmetric shocks that subsequently lead to high unemployment in a subset of the members of the union.

4. Fiscal transfer happens if region-specific shocks prevail, a federal fiscal system would provide regional insurance ( in the form of federally funded unemployment insurance benefits), thereby attenuating the impact of regional shocks on interregional income differential

5. Entering an OCA also imposes a "discipline" on individual countries as it frees the central banks from the urge to embark on inflationary policies.

6. Reducing any speculative attacks as countries are reinforced and also deterred from pursuing uncoordinated economic policies like "beggar thy neighbor", which any violations in conducting a such policy would render a negative impact on all the countries.

Frankel and Rose (1998) mooted the idea that some of the OCA criteria discussed can be endogenous. Once a group of countries establish a currency area by permanently fixing their exchange rate, the degree of intra-area economic integration will increase along with the degree of symmetric of economic shock. Hence deeper economic integration and symmetric of shocks 
are not the prerequisite of establishing a common currency area or other degree of monetary cooperation. Instead, if these countries exhibit a strong political commitment to coordinate monetary and exchange rate policies, then their attempt to form a currency area can be successful as long as they satisfy the OCA criteria to some extent initially

Eichengreen and Bayoumi (1999) try to analyze the economic and political prospects for monetary integration in East Asia, and according to particular criteria, namely the high level of trade and FDI integration, speed of adjustment to shock and symmetric supply and demand disturbances, come up with the conclusion that the region satisfies the standard OCA criteria for the adoption of a common monetary policy. However, a major deterrent to this process is the issue of sacrificing monetary autonomy especially given the weak financial system in a number of these countries.

Looking at the evolving trade pattern in Asia, Kawai and Motonishi (2005) find that in the last decade there has been a rapid expansion of intra-regional trade as well as intra-industry trade. Moreover, intra-regional trade as a share of total trade in East Asia has risen from 35\% in 1980 to 54\% in 2003. In terms of FDI integration, Japan, United States and EU are considered equally important for foreign investors in East Asia, with Japan being the most significant in ASEAN region.

In terms of degree of labor market integration seems to vary across the countries of the region. Developed economies such as Japan and Korea have maintained tight restriction on labor mobility. Meanwhile, Southeast Asian economies such as Malaysia, Thailand, Singapore, and Indonesia are categorized by much greater labor mobility. Both Eichengreen and Bayoumi (1999) and Goto and Hamada (1994) note that labor markets are more flexible in Asia that they were in Europe in Early 1990s.

According to Mundell seminal paper which were stated that the system of national currencies connected by the existence of flexible exchange rate. Subsequently, he came up with the idea that the need of establishing a system of currencies where currencies are not defined by national border, but by geographic areas within which factor mobility is high. Mundell, later on, argue that the choice between fixed and flexible exchange rate regime should not be independent of the economic characteristics of the countries or areas in question (Tower and Willett, 1976).

Based on OCA theory, the wisdom of joining a monetary union can be decided using three major factors. These are the extent of trade intensity between the countries in the proposed area, the symmetry of economy activity and country-specific characteristic (Ling, 2001). Mckinnon (1963) stated that highly open economies are recommended in satisfying for OCA as a common 
currency is very important for their stability and prosperity. This paper would concern in analyzing the existence of asymmetric shocks and country's GDP as proxy to meet the criteria of establishing OCA.

Asymmetric shocks are another important element of OCA theory, as they tend to undermine the case for common currency. According to Frankel \& Mussa (1980), asymmetric shocks occur when an unexpected disturbance affects one country's national output differently from another. The OCA literature stresses that similar shocks across a monetary union's participating countries are likely to reduce the cost of forgoing the exchange rate as a shock absorbing mechanism. On the other hand, the retention of the exchange rate as an independent policy instrument is crucial if a country face mainly asymmetric shocks (Ling, 2001). The diminution of autonomy as an impact of the loss of an independent monetary policy in implementation of OCA would be envisaged more costly when : (1) macroeconomic shocks are more "asymmetric", (2) monetary policy is a powerful instrument for offsetting such shocks, and (c) other adjustment mechanism, such as relative wages and labor mobility, are less effective (Eichengreen, 1997).

In the face of these concerns, Mundell suggested that a common currency is able to mitigate asymmetric shock because it involves a pooling of the members' reserves and a more diverse investment portfolio. In a monetary union, a country that suffers from an adverse shock effectively "shares" the loss with its trading partners, because the partner hold a claim on each other's output through the common currency. Under a flexible exchange rate however, no such portfolio diversification exists and a country facing an adverse shock may suffer devaluation. The domestic currency and its assets would buy less on world markets and the cost of the shock would be confined largely to the country within which the shock originated. In short, we hypothesize that there is a positive association between asymmetric shock and ERV.

Existing OCA theories are primarily related to the choice of exchange rate regime. They also tend to focus on country-specific variables that do not change very much over time. Devereux and Lane (2003) proposed the use of relative size of the gross domestic products (GDPs) of two countries as a proxy for size. Size, measured as the log of the product of the GDPs of countries $i$ and $\mathrm{j}$, can be considered a proxy for the microeconomic benefits of exchange rate stability. In other word, smaller countries are expected to be less willing to tolerate fluctuations in their nominal exchange rate. Hence, we expect a positive relationship between ERV and a country's GDP. 


\section{METHODOLOGY}

As abovementioned that the present study is likely to investigate the relationship between ERV and OCA variables, i.e. asymmetric shocks, and size. Our purpose is to justify the feasibility of the OCA idea within ASEAN5+3. Our empirical model is specified as follows :

$$
\mathrm{ERV}_{\mathrm{t}}=\beta_{\mathrm{o}}+\beta_{1} \mathrm{OCA}_{\mathrm{t}}+\mu_{\mathrm{t}}
$$

Where, ERC constitutes as the nominal exchange rate volatility and OCA is the optimum currency area. Substituting the proxy for OCA, we may get :

$$
\mathrm{ERV}_{\mathrm{t}}=\beta_{\mathrm{o}}+\beta_{\mathrm{o} 11} \mathrm{ASt}+\beta_{\mathrm{o}} \ln \mathrm{SIZE}_{\mathrm{t}}+\mu_{\mathrm{t}}
$$

AS represents as asymmetric shocks, and a positive relationship is expected between this factor and ERV. The higher the level of the AS between two countries, the more profound is the more-adversely affected country's desire to have a flexible adjustment mechanism or flexible exchange rate to absorb and mitigate the impact of the shocks. Meanwhile, size indicates the interaction between core country's GDP and that of corresponding ASEAN5+3 countries. As mentioned in Devereux and Lane (2003), this variable is a proxy for country-specific characteristics and captures the notion that the smaller country will not be able to tolerate variations in the exchange rate. Hence, we expect the sign to be positive.

ERV is measured as a moving average of first-differenced nominal exchange rate, with an order of three ( $m=3)$, as follows:

$$
E R V_{t}=\left[\left(\frac{1}{m}\right) \sum_{i=1}^{m} E R_{t-1-i}-E R_{t-1}\right]
$$

The measurement of AS is quite similar to the measurement of ERV. AS is proxied by an absolute growth differential value, or:

$$
A S_{t}=\left[\left(\text { growth }_{k, t} \text { growth }_{j, t}\right)^{2}\right]^{2}
$$

where the subscripts $k$ and $j$ stand for country $k$ and $j$, respectively.

Many forms of economic time series data exhibit common features such as periods of stationarity. However, it is only recently that time series econometricians have formalized the concept of common co-movements at particular frequencies in econometric models, together with the idea that common factors may influence the trend component of some macroeconomic 
variables. Nevertheless, the statistical underpinnings of time series analysis require that the data be stationary. This will require a first-difference for most macroeconomic series before estimating the economic model. Hence, the significance of detecting and rectifying the trend component in macroeconomic data is sufficiently indicated.

If two or more variables have a common trend, then causality must exist in at least one direction. Many series, even those which are non-stationary, when examined separately, will display a long-term equilibrium relationship if they are joined linearly (Engle \& Granger, 1987). Hence, both series are said to be cointegrated. Cointegration tests are concerned with the long-term behavior of the components of partially non-stationary time series elements - this is an indication of a common trend component. In other words, cointegration is the statistical approach that tests for the existence of a long-run equilibrium relationship among non-stationary variables integrated in the same order. Two non-stationary series are said to be integrated if there exists a linear combination of the two series. For this purpose, Johansen and Juselius (1990) have introduced two likelihood ratio tests to determine the number of cointegrating vectors, namely the maximum eigenvalue and trace tests.

However, given the endogenous nature of OCA variables, it is also very important to analyze the dynamic short run relationship among the variables in the study. The cointegration between two or more variables is sufficient to indicate causality in at least one direction (Granger, 1988). The causality between predetermined and dependent variables can be examined by conducting the Wald test, that is, by calculating the F-statistic based on the null hypothesis that a set of coefficients on the lagged values of independent variables are equal to zero. If the null hypothesis is accepted, it can be concluded that the independent variables do not cause the dependent variable.

The long run relationship between ERV and OCA variables is tested using cointegration procedures. Seven types of exchange rates were chosen, namely Yuan/SD, Yen/SD, Won/SD, $\mathrm{RM} / \mathrm{SD}, \mathrm{Bath} / \mathrm{SD}, \mathrm{Pes} / \mathrm{SD}$, and Rp/SD, where SD stands for Singapore Dollar. These rates were tracked over the 1970 to 2008 period, along with data each country's GDP by using data collected in International Financial Statistic, a publication of the International Monetary Fund (IMF).

\section{RESULT AND ANALYSIS}

Using unit root test of Philip-Perron (1988), It appears, in general, that all variables are non stationary at level in each country. the use of the error vector correction procedure is appropriate, given the evidence that generally all variables are seemly integrated of order of I or I(I). Table IV.2 provides the results of the cointegration test, shown by the significant of 
trace and maximum eigenvalue tests. From the results of the Johansen cointegration test, the null hypothesis of no-cointegration is rejected at the 0.01 significance level for 2 countries, namely Thailand Bath and Peso Phillipines. The remaining are seemly not likely to show no cointegration so that those considered are not having a long run equilibrium. A summary of the overall result is presented in Table IV.2.

The estimated error correction model (ECM) for each equation is presented in Panel I of Table IV.3. This provides further evidence that there exists a long-run equilibrium among variables. The ECT reflects the adjustment process on the path towards this long-run equilibrium. From Panel II in Table IV.4, it is apparent that the standard error of regression for each model is generally low. The robustness of the model is affirmed by diagnostic tests, including the LM test (Breusch-Godfrey serial correlation test), the ARCH test (heterogeneity test), the JacqueBera test (normality test) and the CUSUM test (stability test) under $1 \%$ critical value. From the ECM, it appears that the lagged period of the error correction term (ECT) in each equation enters significantly with a correct sign and magnitude. However, according to the results, we could explain that not all countries within the region which are showing a correct sign and magnitude as expected in earlier hypothesis. Bath Thailand, Peso Phillipinnes, Ringgit Malaysia, Won South Korea, and Yen Japan seem to appear as insignificant sign since their's GDP and existing asymmetric shocks across and over the countries. Therefore, this provide some evidence that the ASEAN5+3 are considered not really ready to form OCA. It corroborates the existing opinion that the different in economic structure and its policies over foreign environment are becoming some barriers and challenging area to synchronize in the following time.

Turning to the impact of AS, it appears that its contribution to volatility is relatively high, since the newly industrialization countries, such as China and South Korea are starting to foster and expand their's economic size and scope to more competitive. The intensity of trade of those countries has added up the possibility of asymmetric shocks across countries within the region. The equations also outline that Malaysia's, Indonesia's, Japan's, South Korea's, and China's economic performance are becoming similar to that of Singapore's, is that in terms of unexpected disturbance affects one country's national output differently from another (Frankel and Mussa, 1980). This development may be explained by the similarities in the production structure of ASEAN economies, as well as by the parallel movement towards greater openness, for example, in the form of a more export-focused orientation and the liberalization of capital accounts. Similarly, the contribution of AS to ERV is relatively low for Thailand and Phillipinnes. Therefore, in general, the level of AS suffered by the ASEAN5+3 economies is not very high. What exists instead is a high degree of shock symmetry (Madhur, 2002). In short, the significant and positive impact of AS on ERV suggests the existence of 


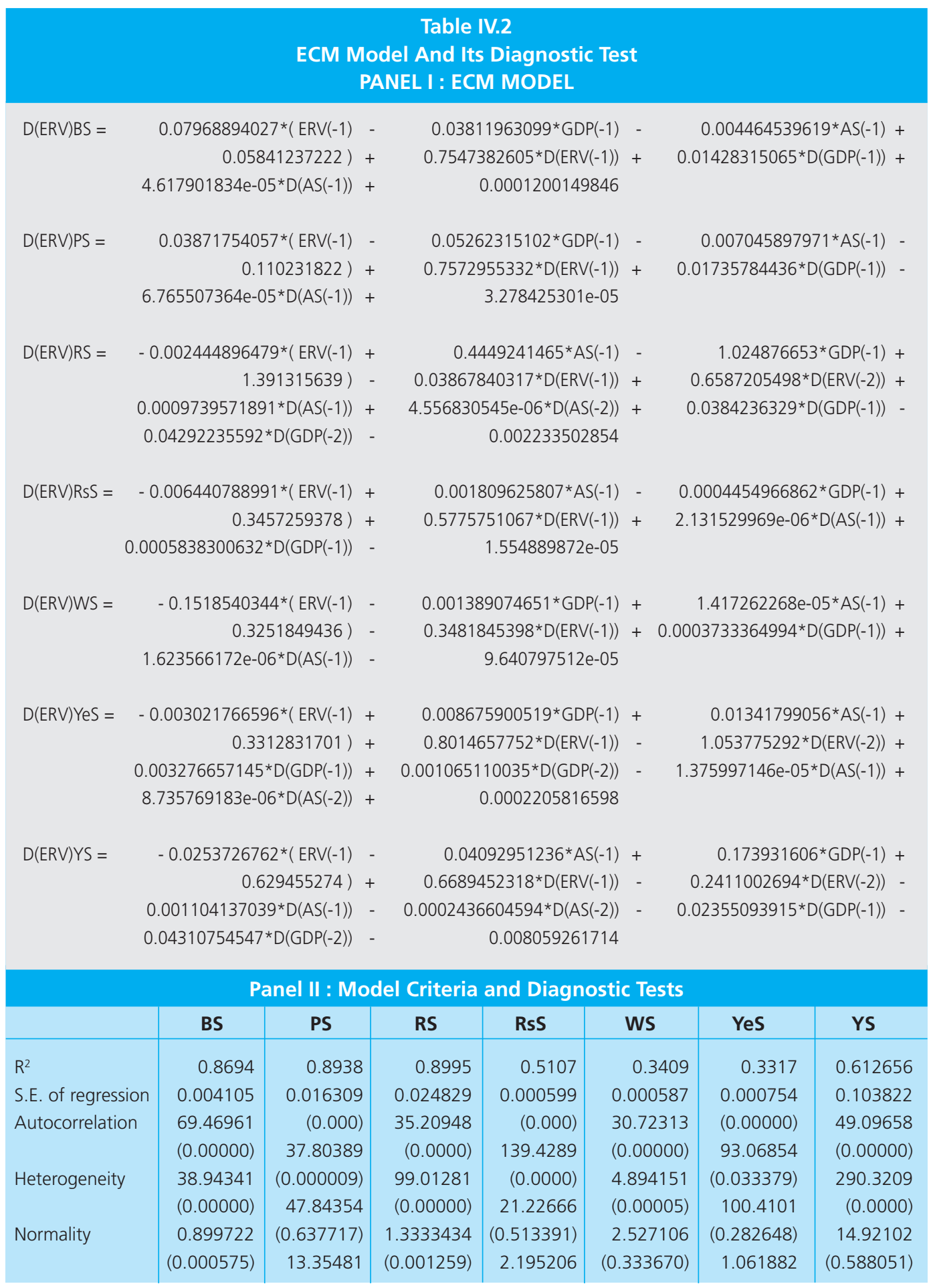

Notes : Figure in ( ) p-value and the test is based on F-Test

$\mathrm{BS}=$ Bath/SD,PS = Peso/SD, RS = Ringgit/SD, RsS = Rupiah/SD, WS = Won/SD, YeS = Yen/SD, YS = Yuan/SD, SD = Singapore Dollar

$\star * *, * *, *$ are McKinnon $99 \%, 95 \%$, and $90 \%$ critical values, respectively 


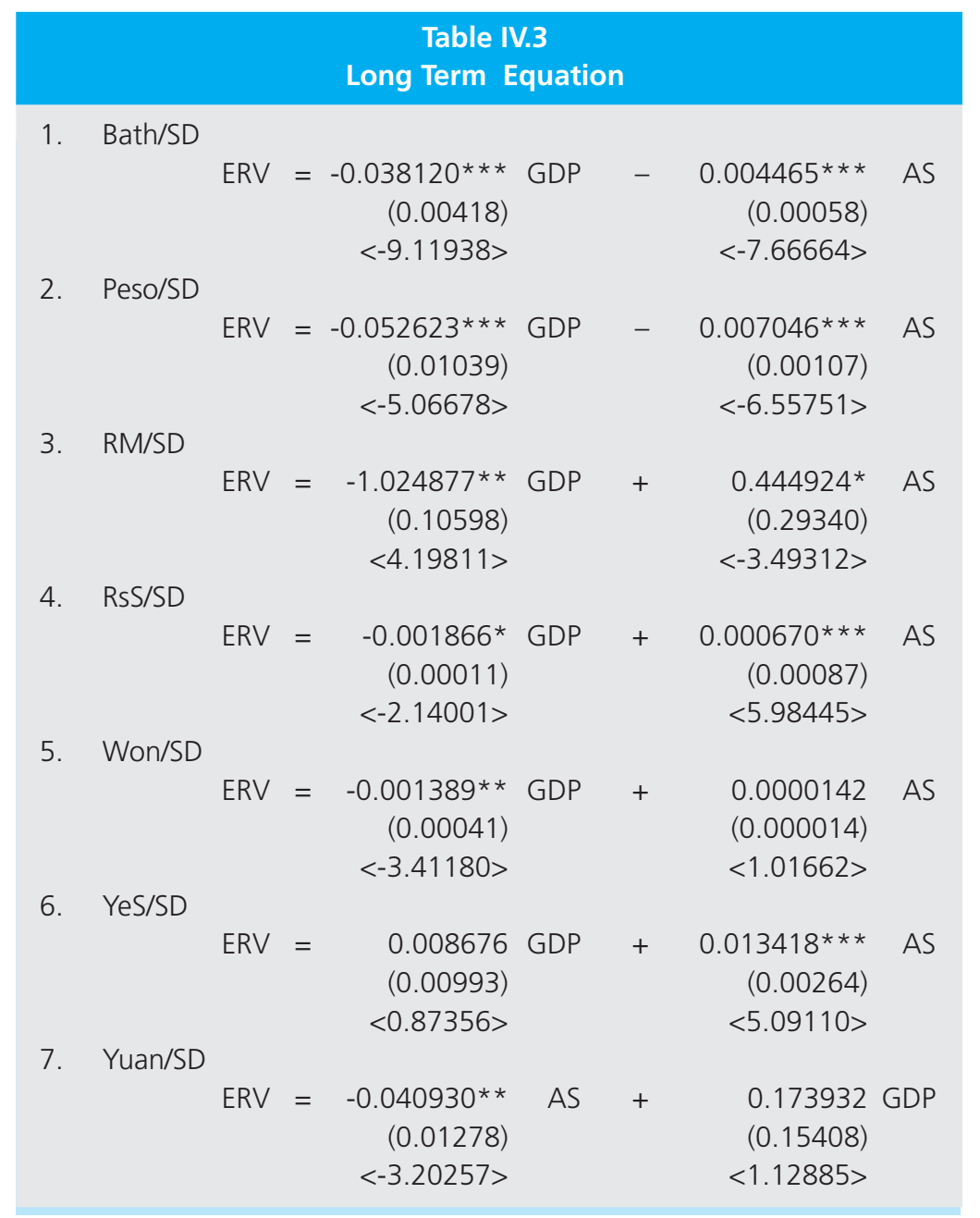

slight differences between Singapore and its ASEAN5+3 economies. This observation also implies the need for adjustments when the economic condition of a trading partner changes unexpectedly. Therefore, we may conclude that ASEAN5+3 countries are not appropriate to form a monetary union which are under the concept of optimum currency area in regards with asymmetric shocks emerge. Similarly, the results have indicated the fact that the possibility of the occurrence in asymmetric shocks imply any fluctuations in currencies's stability in other countries within the region. Hence, the positive impacts AS to ERV which are incurred in ASEAN5+3 economies indicate the existence of inappropriate condition to form OCA since there are no similar shocks across a monetary union's participating countries. Under such condition, it would foster the costs of forgoing the exchange rate as a shock absorbing mechanism. 
In all cases, SIZE plays only a minor role in explaining real ERV. Its effects appear to be in correct signs and magnitude as expected earlier in all observed countries except in the case of the Yen in relation to the SD. The equations show small results and the SIZE element remains negative. It implies that the economies are big enough to absorb any shocks. Given the relatively small value of their coefficients, we can say that there is a growing trend for ASEAN5+3 economies to develop their own capability in handling the shocks as well as a tendency to have and implement stable exchange rate regime. In other words, the ASEAN5+3 countries are attempting to maintain their regime of currency. It deserves to argue that those observed countries still are resisting their existing regime since they are till believing that they begin to establish the system of monetary which are able to absorb any possible shocks in regards of their SIZE. In sum, the ASEAN5+3 countries are considered to fulfilling the requirement to form currency optimum area which are able to main their stable currency.

The results of the short-run Granger causality tests are presented in Table IV.6. Short-run Granger causality appears to run mainly from the ERV to each of the OCA criterion, although the short-run impact on GDP and AS is almost insignificant in the case ASEAN5 countries and significant at critical point in the case of China Yuan, Taiwan Won, and Yen Japan. Meanwhile, the short-run Granger causality running from each of the OCA criterion to ERV or other OCA criterion is less apparent. Therefore, the disequilibrium in the short-run may be due to the shock of the ERV.

We attempted to examine the severity of the ERV impact on real economic activities more closely. Focusing on the second column of Table IV.4, the short-run Granger causality from ERV into each of the OCA criterion becomes clear. The sign in the bracket stands for the direction of the impact of the ERV on each of OCA criterion. Although many studies that utilize the VAR model (i.e. VECM) investigate the direction of impact by using impulse response functions (IRFs), we chose not to focus on the IRFs and instead simply sum up the coefficients of the short-run impact of the ERV. This method of quantifying the short run effect by summing up the coefficients is commonly carried out as part of ARDL procedures. When there is more than one lag of the VAR model, the short-run coefficient (or impact) is estimated by the summation of first-differenced ERV coefficient, while the significance of the impact is tested by an F-test based on Wald-test procedure.

According to Granger test, we found that only Thailand, Taiwan, Japan, and China which are delivering the short run effects to observed variables. While the short-run impacts of ERV on GDP and AS are positive for those following countries. Meanwhile in the case of Thailand, GDP has caused over the existence to AS. It constitutes the fact that the Thailand economy would be suffered a shock through the fluctuation in it's GDP. Subsequently, Indonesia, 


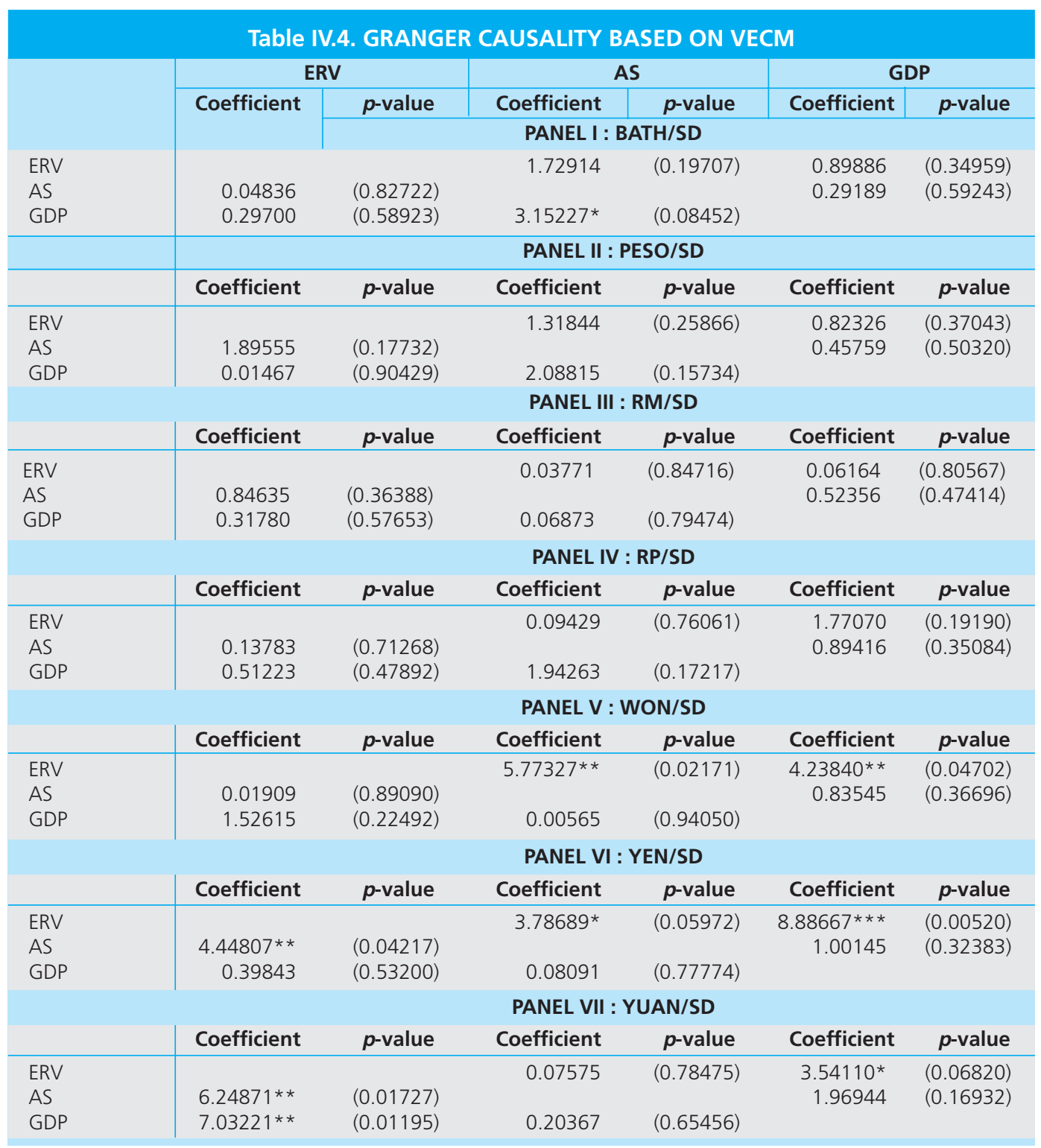

Notes : Figure in ( ) p-value and the test is based on F-Test. SD = Singapore Dollar

$* * *, * *$, ${ }^{*}$ are McKinnon $99 \%, 95 \%$, and $90 \%$ critical values, respectively

Malaysia, and Phillipinnes seem not to show any causal relationship between variables OCA and ERV.

Basically, ERV, which is used as a proxy for miscoordination, can contribute to greater divergence, instead of convergence, among ASEAN members. In short, we found that ERV has in general contributed negatively to the level of real economic activity. Both generally and empirically, we found that all OCA variables play an important role in explaining the ERV, and 
thus in the choice of an exchange rate regime. The question then arises as to why the idea of a common or single currency has not been even remotely realized. From the empirical results, possible explanations include smallness, coordination, the choice of currency, as well as labor immobility.

As mentioned earlier that OCA is a geographical region in which it would maximize economic efficiency to have the entire region share a single currency. It describes the optimal characteristic for the merger of currencies or the creation of a new currency. The theory is utilized often to argue whether or not a certain region is ready to become a monetary union, one of the final stages in economic integration. In this sense, the successful of establishing of OCA in the area of ASEAN5+3 countries.

A successful move towards an OCA basically need to overcome a number of obstacles that are usually associated with greater economic and monetary integration. We may have taken a close look at some of these constraints in order to mitigate the barriers and keep a right track in forming OCA agenda.

\section{CMI Framework: Weak Institution?}

In any kind of a formal exchange rate arrangement within a region there is need for a mechanism providing some degree of collective defence against speculative attacks on a single currency. The recently developed Chiang Mai Initiative (CMI) can provide some institutional support against such speculative attacks. Following deliberations in Chiang Mai in May 2000, Japan, China and South Korea signed bilateral agreements with the original five ASEAN member countries establishing a network of bilateral swap agreements (BSAs) aiming at greater monetary cooperation. The network enabled participating countries to draw from their respective BSAs for a period of 90 days. The first drawing could be renewed seven times. The interest rate applicable to the drawing is the LIBOR plus a premium of 150 basis points for the first drawing and the first renewal. Thereafter, the premium increases by 50 basis points for every two renewals, within an overall ceiling of 300 basis points. The currency swaps amounted to over $\$ 83$ billion in July 2007. To mitigate the problem of moral hazard, these BSA swaps are linked with IMF disbursements. A country can borrow only up to $20 \%$ if it is not under an IMF programme.

Apart from benefits arising from nominal swaps, the BSAs signal political and economic support in the event of a financial distress. If the ACU (Asian Currency Unit) is to become a viable parallel currency, the Chiang Mai Initiative has to play a very important role. Unfortunately, the current structure of the CMI has several shortcomings that can reduce it's effectiveness. In it's present form CMI is primarily bilateral in nature. The use of BSAs requires approval from 
each lender. Under such circumstances, if a number of members refuse to provide swaps or various swap providers demand different terms and conditions, the CMI looses it's effectiveness as a lender of last resort. Moreover, discussion with various swap providers is time consuming and deprives swap requesting countries of the ability to mount an effective and prompt defence against speculative attacks. Thus steps should be taken to multilateralize the existing bilateral swap arrangements so that swap disbursements are made in a concerted and timely manner.

The BSA facility is only a small step towards financial cooperation in the region. The current size of the swap facility has only marginally increased the financial resources available to countries for helping them to meet their liquidity needs, and is inadequate to prevent a financial crisis of the kind witnessed in 1997. Moreover, only $20 \%$ of the BSA facility is immediately available to the borrowers while the remaining $80 \%$ requires IMF approval and hence is subject to IMF conditionalities. Such linkages preserve the hegemony of the U.S. in the regional financial framework, something that the Asian countries are keen on breaking.

CMI's current structure also ensures that participating countries do not feel an urgent need to establish a central agency for conducting regional surveillance. The absence of a central body to manage the resources and monitor the financial developments in the region is a serious impediment to the evolution of a joint decision making process. Recognizing these shortcomings, the ASEAN+3 ministers agreed to take steps to enhance the effectiveness of the CMI. These include further integration and enhancement of ASEAN+3 economic surveillance into the CMI framework, clear definition of the swap activation process and the adoption of a collective decision-making mechanism, increase in the size of swaps, and improvement of the drawdown mechanism.

\section{Inadequate Surveillance in the Region}

Effective regional surveillance of national policies is a prerequisite for countries attempting to adopt a singular currency or undertaking looser forms of monetary cooperation. One of the primary reasons for linking the BSA's activation to the IMF is due to the availability of a credible surveillance mechanism with the Fund for member countries. During the fallout of the Asian crisis, the need for some sort of an Asian surveillance mechanism was recognized and it's objective was to devise an early warning system to prevent similar crises in the future as well as limit the impact of cross country contagion during the fallout of the Asian crisis.

The ASEAN-5+3 countries have an existing system of surveillance process with technical assistance from the Regional Economic Monitoring Unit (REMU) of the ADB called the ASEAN+3 
Economic Policy Review and Dialogue Process. The process includes the preparation of a confidential staff report by the ADB, which is reviewed by the policymakers of the member countries. The report is thereafter discussed at a finance ministers' meeting and is brought out as an agreed ministerial statement.

The inherent structure of the entire review and surveillance process reveals several glaring inadequacies. Firstly, since the staff knows that the final document is going to be vetted by the various ministers, it is likely to be largely inoffensive in nature and unlikely to underpin countries following policies that could be destabilizing for the region. Such a document, as evident from the recent ministers' statements, is unlikely to encourage discussions about the incipient risks in the region Moreover, unlike the IMF surveillance, the ASEAN-5+3 process does not specify the precise content of the information each government needs to provide. Consequently, the information available to the various members is at the discretion of the reporting country. This makes it very difficult to draw comparisons among the various countries and provide policy related conclusions.

This lack of independent and credible surveillance to monitor economic and financial developments in the region is a significant obstacle to greater economic and monetary integration. This is, of course, not to suggest that the Fund's surveillance mechanisms, essentially in the form of Article IV consultations, are decidedly superior. However, compared with the perceived lack of teeth in the ASEAN-5+3 surveillance mechanism, there are probably important lessons to be learnt from the more upgraded system of the Fund.

\section{Underdeveloped Bond Market}

A deep and well developed bond market facilitating orderly cross country flows of debt within the region is an important prerequisite for the ACU. To that extent the initiative of setting up the Asian Bond Fund (ABF) was definitely a step in the right direction as it enabled the bringing together of Asian economies with different sizes and economic structures. The eleven members of the Executives' Meeting of East Asia-Pacific Central Bank (EMEAP) agreed in 2003 to establish the $A B F$, a regional investment fund investing in bonds denominated in U.S. dollars. The initial corpus was $\$ 1$ billion with the various governments voluntarily contributing about $1 \%$ of their reserves. The Fund was supposed to invest in bonds issued by the public sectors of eight countries, the developed countries of Australia, New Zealand and Japan only being lenders to the ABF.

With different countries in the region exhibit varying degrees of current account deficits and surpluses, development of a strong bond market would have enabled useful absorption of 
intra-regional debt flows. However, the initial form of the ABF had severe limitations that required to be resolved for ensuring greater financial cooperation. Firstly, the ABF could invest mainly in dollar denominated securities and was unable to resolve an insolvency crisis of an Asian bond issuer in cases involving a sharp declines in the values of the Asian currencies vis-'a-vis the U.S. dollar like the kind experienced by Thailand and Korea during the 1997 financial crisis. Thus there was a critical problem of 'currency mismatch'. Secondly, majority of the bond issuers belong to the private sector, and they tend to use the funds for long-term investments while foreign lenders are mostly of the short-term variety. When business conditions or expectations worsen, foreign lenders are likely to reduce their risk exposure by withdrawing funds, plunging local business into insolvency. Thus apart from currency mismatch, the Asian Bond Fund also suffered from 'maturity mismatch'. This 'double mismatch' was one of the main reasons for the Asian financial crisis in 1997.

Recognizing the threat of 'currency mismatch' and with the objective of promoting local currency denominated bonds, the ABF-2 was introduced in December 2004. This involved purchases of $\$ 2$ billion of Asian-currency denominated sovereign and quasi sovereign bonds. ABF-2 also introduced a Pan-Asian Bond Index Fund (PAIF) and a Fund of Bonds Fund (FBF). PAIF is a single bond fund index investing in local currency bonds issued by eight countries. On the other hand, the FBF is made up of two tiers. The parent fund is further divided into eight sub funds, each of which invests in the local currency bonds issued in their respective markets.

Size again is a major weakness of this initiative. The current size of $\$ 2$ billion is insignificant compared to the reserve holdings or the infrastructural financing requirements of most of these countries. Second, the Fund covers only eight Asian economies excluding some ASEAN members as well as other significant economies like India. Thus there is tremendous scope for improving both the coverage and the size of the regional debt market. Moreover, owing to the limited supply of good quality sovereign and quasi-sovereign bonds, initiatives like the ABF can actually crowd out private bond purchases leading to no new net financing.

\section{Diverse Exchange Rate Regimes}

The European experience indicates that the presence of a common monetary regime, i.e. pursuit of region wide exchange rate stability, played a key role in evolution of greater monetary cooperation. However, Asian countries follow a diverse range of exchange rate regimes. While a number of the Asian currencies including Indian Rupee, Singapore Dollar, Thai Baht, and Malaysian Ringitt can be classified as managed floats, other countries are following different 
exchange rate mechanisms. Brunei Dollar and Chinese Renminbi continue to be pegged mainly to Singapore Dollar and U.S. Dollar respectively. On the other hand, Japanese Yen, Korean Won, Indonesian Rupiah and Philippine Peso are freely floating.

Such diverse exchange rate arrangements in the Asian region reflect the different objectives followed by the monetary policymaker. These range from fixing the exchange rate with another country in a currency board system to import the latter's monetary policy, to keeping the exchange rate undervalued to promote export led growth, and explicit inflation targeting. Reconciling such diverse objectives within the region is bound to be a challenging task.

\section{Economic, Historical and Political Heterogeneity}

While arguing for greater economic integration in Asia, it is important to keep an eye on the political, economic and historical differences between the countries in the region. Asian countries differ widely in terms of economic structure and level of development. Divergence in per capita GDP between the former is much higher than that in Europe or North America. In 2006, Japan and Singapore's per capita GDP in PPP terms was nearly 15 times that of Lao PDR. Similarly, share of exports in GDP range from below 15\% in Japan to well over 100\% in Malaysia and Singapore. Several countries like China and the newer ASEAN members have extensively regulated financial systems and are unlikely to release operational control in the near future.

Moreover, while in Europe, Germany took the lead role in pushing towards monetary integration, there is an absence of a clear leader in the Asian region. Japan is the most developed country in the region but has unsettled historical issues with neighbouring countries like China and Korea. Thus any bloc with Japan as the sole center is unlikely to find many takers in Asia. China, owing to it's size and an impressive growth over the last 25 years, can be another potential centre. However, it's relatively underdeveloped financial architecture, inconvertible currency, and a central bank with limited autonomy can be major impediments to any such claims. Moreover, China also has it's share of unresolved issues with Korea and India. Also it is likely to face competition from India, another big and rapidly growing economy of the region, in it's pursuit to emerge as the core of a regional currency arrangement.

The absence of a central country till now means that Asian cooperation needs to rely more on a symmetric approach. Such cooperation requires a strong region wide political commitment. The vast heterogeneity among countries, however, impedes the fostering of political will. The Asian countries have wide differences in social structures, and economic systems, ranging from mature market economies like Japan and Korea to economies in transition like China, India and Vietnam. Although, in recent years countries have cooperated in areas of 
security and strategic interests, residual Cold War attitudes might still constrain greater economic and monetary cooperation. One of the key issues in this regard is the strategic relationships that many countries in the region have with the US, which might create an ambiguity in pursuing Asian regionalism. There exists doubts over whether regionalism would provide greater benefits than multilateralism in the region. Such arguments have influenced several countries in Asia and discouraged the build up of the political consensus needed for closer cooperation. The process has become more difficult due to the wide divergence in political systems and institutions in the region (eg. non-democratic governments in China and Myanmar and mature democracies in India, Japan and Korea)

\section{STRATEGIES}

A successful move towards an Asian Currency Unit needs to overcome the above obstacles. Thus the move needs to be supported by two sets of factors. Firstly, certain institutional safeguards have to be created or the existing ones strengthened, for preventing the participating countries from breaking away from such an arrangement. Secondly, strategies need to be devised for promoting the use and acceptability of this parallel currency. We list below some of the safeguards and strategies that in our opinion are key to the success of the ACU.

\section{V.1. Periodic Review of the Asian Currency Unit (ACU)}

Given the extent of dynamism in most of the Asian economies, it is very important to periodically review the composition of the ACU for ensuring that it reflects current economic realities. The amount of each component currency will remain fixed while it's contribution to the ACU will vary with the exchange rate. As currencies appreciate (depreciate), there will be an increase (decrease) in their contribution to the ACU. This will ensure that the ACU captures the relative changes in economic activity and performance in the region in an effective and dynamic manner.

\section{V.2. Monetary and Exchange Rate Cooperation}

A move towards an ACU would necessitate significant monetary and exchange rate cooperation among the participating countries. Given the differences in the exchange rate policies and inflation rates among these countries, a system as tight as the ERM will not be feasible. Several other alternative proposals have been mentioned, each of which has it's merits and demerits. 
Williamson (1999) proposed that the Asian economies can adopt a common currency peg vis-'a-vis the U.S. Dollar, Euro and Japanese Yen. This would stabilize exchange rates both internally as well as vis-'a-vis other major trading partners, Euro Area and the U.S. Under this arrangement the member currencies have a common set of weights based on the regional trade shares. The members announce a central parity vis-'a-vis the basket and pledge to keep the central parity within a unilaterally chosen band. The central parity and the band is allowed to crawl in response to changes in the fundamental. In response to massive speculative attacks countries are allowed to temporarily suspend the peg with a credible pledge to return as soon as possible.

The biggest advantage of this arrangement is that it allows coexistence of the various exchange rate regimes prevailing in the region like managed float in India, Thailand and Singapore, independent float in Korea and the peg in China. Furthermore, while there is less need for policy coordination and surveillance under this arrangement due to a unilaterally chosen parity and band, the arrangement itself acts as a catalyst for greater convergence and exchange rate stability, which is needed for a future move towards a common currency as pointed out by Kawai and Takagi (2003). However, a major problem in this arrangement is the adoption of common regional weights against the target currencies. If some participating country's trade share (weights) vis-'a-vis the target countries is very different from the region as a whole then a change in the bilateral exchange rates of the target currencies will have a skewed impact on these countries and they will experience a loss of export competitiveness.

Another alternative arrangement suggested by Oh and Harvie (2001) analyzes the potential of replicating the EMS's Exchange Rate Mechanism in the Asian region, with notable differences. Under this arrangement, an Asian Currency Unit similar to the one developed will be put in place. The member countries' exchange rate will float within $a \pm 15 \%$ band of the central parity determined by an authority. Such an arrangement comes with several benefits. It will significantly reduce interregional volatility of the nominal exchange rate as well as real effective exchange rate (REER) resulting from intraregional parity changes and a greater degree of comovement of the intraregional exchange rates. It will also induce faster economic and monetary integration in the region. However, since the target is a basket of member country currencies, realignments between major currencies outside the basket will not be reflected in the bilateral exchange rates. On the other hand if the U.S. Dollar depreciates against the Euro but not the Japanese Yen then exports from countries pegged to the U.S. Dollar will become more competitive in Euro land compared to these Asian economies. Similarly, if the Japanese Yen appreciates by $10 \%$ against the U.S. Dollar and Japan has $50 \%$ weight in the ACU, then other members of the ACU will witness a $5 \%$ appreciation, which may reduce their competitiveness 
vis-'a-vis other dollar bloc countries.

Dornbusch and Park (1999) floated the idea of monetary cooperation among Asian economies with the Japanese Yen as the anchor currency, a role performed by the German Deutsche Mark under the ERM. However, given that the Japanese economy has not been in very robust health in recent years it might be difficult to push for this proposal. Moreover such an arrangement will entail a loss of competitiveness of Asian exports vis-'a-vis other dollar blocs like MERCOSUR and NAFTA if Japanese Yen appreciates against the U.S. Dollar.

\section{V.3. Establising A Centre Country}

One of the commonly cited reasons for the successful monetary integration in Europe is the central role played by Germany. It is widely believed that the presence of a strong currency, Deutsche Mark, which acted as a nominal anchor in the EMS, facilitated the integration. Moreover the Deutsche Mark was backed by the strong Bundesbank - which focused on price stability and created an independent monetary policy committee - features that have become trademarks of modern central banks. While in hindsight the role played by Germany seems to be pivotal for European integration, at that time such a role was not planned and, when it existed, was studiously underplayed. Formally, the EMS was a set of bilateral exchange rate arrangements with no central currency. Economically strong and weak countries were subject to identical obligations and interventionist rules. The emergence of the Deutsche Mark as the nominal anchor took several years and was facilitated by irresponsible monetary management by other large economies in the region, which led to speculative attacks on their currencies and sapped their positions.

In the Asian context, while it is true that some form of country leadership is desirable, such leadership should not be seen as intimidating and must be counter balanced. In doing so, political and historical sensitivities, as well as current power configurations must be kept in mind. While Japan continues be a major player in the region, China and India have begun mounting serious challenges to Japan's hegemony. Hence a cohesive move towards greater Asian integration must take shape around these few leading countries. The absence of a single centre of influence will ensure that the leadership is balanced

\section{V.4. Strengthening the Chiang Mai Initiative and the Asian Bond Fund}

At the ASEAN+3 Finance Minister's meeting held in Istanbul during May 2005 it was decided by the participating countries to make several changes in the existing CMI structure. Apart from agreeing to integrate economic surveillance into the CMI to develop an effective regional 
surveillance, the member countries also agreed to adopt a collective decision making mechanism as a first step towards multilateralization. It was also decided to expand the size of the bilateral agreements and increase the amount a country can draw without having an IMF program.

While the amount that a country can draw without being subject to an IMF program has been increased from $10 \%$ to $20 \%$, not much progress has been made on the other issues. The combined size of the network of BSAs has increased from $\$ 36.5$ billion in April 2004 to $\$ 83$ billion in July 2007 . Strong measures need to be undertaken to further increase the size of this arrangement. One possible way is to invite new members like India, which has almost $\$ 300$ billion as reserves, into the arrangement. Moreover, almost all the bilateral swaps are negotiated between China, Japan, Korea and the original ASEAN countries. The smaller ASEAN members like Brunei, Cambodia, Laos, Myanmar and Vietnam are covered only by the ASEAN Swap Agreement, which has a corpus of a measly $\$ 2$ billion.

Similarly the Asian Bond Fund also needs to be increased from it's current size and coverage. Newer countries like India as well as other ASEAN economies can be invited to join the fund. There is a serious need to amplify the corpus of funds available with the ABF for it to play a deciding role in deepening capital market integration in the region. Thus the central banks of the participating countries need to commit greater resources to the Fund. In it's current form the $A B F$ is managed by the Bank of International Settlements (BIS) an association of global central banks. Thus the business of investing these funds is primarily in the hands of central bankers who tend to be more conservative and willing to sacrifice return for liquidity. To ensure greater development of international capital markets in the region, participation of the private sector in the form of investment bankers and institutional investors in the ABF needs to be encouraged.

\section{V.5. Asian Monetary Cooperation Fund}

Apart from strengthening the Chiang Mai Initiative and the Asian Bond Fund, the Asian countries could create a regional fund denominated in the ACU. Such a fund could be used to facilitate interventions in the currency markets, effect liquidations between the central banks and manage short-term credit facilities associated with exchange rate cooperation. This fund could be created by tapping the enormous amount of foreign reserves of East and South Asian countries. Each member country could contribute a certain percentage of their foreign reserves into the fund. Given that the total reserve holdings of the economies considered is in excess to $\$ 3$ trillion, even if these countries contribute $10 \%$ of their reserve holdings, a fund with over $\$ 300$ billion will be created. 
If the exchange rate of a participating currency falls too far, the Asian Monetary Cooperation Fund (AMCF) could buy quantities of the currency on the foreign exchange market, and if it rises too far, AMCF could sell enough of the currency to bring down the exchange rate. Alternatively, the AMCF could also issue a parallel currency, Asian Currency Unit, which would be a weighted composition of member countries' currency. ACU denominated bonds can be encouraged and a regional clearing and payment mechanism can be established for ACU transactions. Over time the AMCF can be converted to Asian Central Bank and assume the role of conducting monetary policy in East and South Asia.

The corpus available could be used to fund several developmental needs of the region. Primary among these uses could be financing infrastructural investment. Many countries of the region like India, Vietnam, Indonesia etc. are facing massive infrastructure deficits, especially in physical infrastructures like highways, power, airports etc. The AMCF could allocate funds, denominated in ACU, for such projects. This would not only help mitigate the massive infrastructure deficit in the region but also promote the public and the private sector use of ACU. Other developmental needs that could be funded by the AMCF include social infrastructure like health and education, environmental protection and strengthening of the financial sector, among others.

\section{V.6. Implementing an Effective Regional Surveillance System}

One of the biggest challenges facing the ACU is the implementation of an effective regional surveillance mechanism. The existing ASEAN+3 surveillance mechanism needs to be significantly strengthened if it is to act as a meaningful instrument for greater economic and monetary cooperation. According to Kenen and Meade (2008) and Girardin (2004) the Asian economies need to move away from the principle of 'non-intervention in other countries' affairs' and actively provide their opinion on the policies followed in member countries. While a confrontational approach involving direct criticism of the neighbouring countries' policies might not be feasible at this stage, several other, less confrontational, measures can be undertaken. Kenen and Meade (2008) and Grenville (2004) suggest a mechanism where the analysis and the recommendations of an independent surveillance team is put before the member country and the government is allowed to respond to the submissions. A healthy debate on major macroeconomic and financial sector issues impacting the reporting country is a must for better surveillance and greater coordination. This underlines the need for greater constructive criticism among the member countries even if it comes at the expense of occasionally overlooking the Asian tradition of not interfering in neighbours' affairs. 


\section{V.7. Greater Integration of Goods and Services Market}

Monetary cooperation in Europe was achieved with the goal of turning Europe into a truly unified market. The 1957 Treaty of Rome founding EU had established a customs union and barriers to goods and services trade were significantly reduced over the next four decades. Thus trade cooperation began long before financial cooperation. On the other hand, in East Asia financial cooperation took lead mainly as a response to the financial crisis of 1997. Such financial cooperation now needs to be complemented with greater trade cooperation in the region. With the likelihood of progress in implementing the Doha Development Agenda appearing highly limited, countries in the region need to enhance trade cooperation through bilateral agreements, rather than relying on multilateral trade talks. It can be clearly seen that while some countries like Japan have been vigorously pursuing bilateral trade agreements, other countries like Philippines and Indonesia are lagging behind.

Preferential or free trade agreements are likely to induce greater cooperation as they are more flexible, wider and relatively easily achievable. Greater market integration through PTA FTAs will not only provide larger market access across the region but will also impart efficiency through competition. In several cases trade agreements can be used as a strategy for pushing domestic reforms. The foundation for Asian economic agreement lies in increasing common economic interests based on economic interdependence. The "flying geese model" helped to build a vertical chain across the region by encouraging capital mobility and technology transfer, thereby formulating a high degree of intra-regional exchange. Such economic interdependence can be further exploited through more free/preferential trade agreements among the region. With greater intra-Asia trade integration, business cycles will be more correlated across countries and it will be easier for the latter to engage in exchange rate cooperation, which is crucial for moving towards an Asian Currency Unit.

\section{CONCLUSION}

The formation of the economic integration, like any regional economic arrangement, serves largely to help foster stability across the region. The formation of economic integration can be further strengthened by the idea of a single currency. The feasibility of economic integration and single currency is the main focus of this study. We investigated whether there is room for OCA variables in explaining ERV in the case of ASEAN-5+3 for the period of 1970 to 2008.

The results provide some evidences that the ASEAN5+3 are considered not really ready to form OCA. It corroborates the existing opinion that the different in economic structure and its 
policies over foreign environment are becoming some barriers and challenging area to synchronize in the following time.

The positive impacts AS to ERV which are incurred in ASEAN5+3 economies indicate the existence of inappropriate condition to form OCA since there are no similar shocks across a monetary union's participating countries. Under such condition, it would foster the costs of forgoing the exchange rate as a shock absorbing mechanism.

It deserves to argue that those observed countries still are resisting their existing regime since they are till believing that they begin to establish the system of monetary which are able to absorb any possible shocks in regards of their SIZE. In sum, the ASEAN5+3 countries are considered to fulfilling the requirement to form currency optimum area which are able to main their stable currency.

According to Granger test, we found that only Thailand, Taiwan, Japan, and China which are delivering the short run effects to observed variables. While the short-run impacts of ERV on GDP and AS are positive for those following countries. Meanwhile in the case of Thailand, GDP has caused over the existence to AS. It constitutes the fact that the Thailand economy would be suffered a shock through the fluctuation in it's GDP. Subsequently, Indonesia, Malaysia, and Phillipinnes seem not to show any causal relationship between variables OCA and ERV.

A successful move towards an OCA basically need to overcome a number of obstacles that are usually associated with greater economic and monetary integration, namely weak institution, Inadequate Surveillance in the Region, Underdeveloped Bond Market, Diverse Exchange Rate Regimes, Economic, Historical and Political Heterogeneity.

A successful move towards an Asian Currency Unit needs to overcome the above obstacles, such as Periodic Review of the ACU, Monetary and Exchange Rate Cooperation, Establising A Centre Country, Strengthening the Chiang Mai Initiative and the Asian Bond Fund, Asian Monetary Cooperation Fund, Implementing an Effective Regional Surveillance System, Greater Integration of Goods and Services market. 


\section{REFERENCES}

Bystrom, Hans N. E. karin Otofsdotter, Lars Soderstrom. Is China an Optimum Currency Area? Journal of Asian Economics 16. 2005. 612-634.

Eicherngreen, Barry. -tahun- Chapter 7, Parallel Process? Monetary Integration In Europe and Asia. -journal of Economics

Frankel, Jeffrey, and Andrew Rose. An Estimate of The Effect of Common Currency on Trade and Income. The Quarterly Journal of Economics, May 2002.

Grauwe, Paul de. - tahun- , Chapter 6, Asian Monetary Unification: Lessons Froom Europe. journal of Economics

Grauwe, Paul de. 1996. International Money Postwar Trends and Theories. Oxford University Press Inc. : New York

Huang, Yin, Feng Guo. Is Currency Union Feasible Option In East Asia? A Multivariate Structural VAR Approach. Research In International Business and Finance 20. 2006. pg 77-94.

Kawasaki, Kentaro. A possibility of Creasing A Common Currency Union In East Asia. -journal of Economics

Kettell, Brian. 2002. Economics for Financial Markets. Butterworth-Heinemann: Oxford.

McKinnon, Ronald. Optimum Currency Areas, and Key Currencies: Mundell I versus Mundell II. Forthcoming Journal of Common Market Studies. August 2004.

Mishra, Ritesh Kumar, Chandan Sharma. Real Exchange Rate Behavior and Optimum Currency Area in East Asia: Evidence from Generalized Purchasing Power Parity. International Review of Financial Analysis 19. 2010. 205-213.

Mundell, Robert A. 1961. Optimum Currency Areas. American Economic Review, 51, 657665

Mundell, Robert. 2005. The Case for A World Currency. Journal of Policy Modeling.

Ricci, Luca Antonio. A model of An Optimum Currency Area. Recent Development in International Money and Finance. Vol 2. March 14, 2008.

Mussa, Michael, Paul Masson, Alexander Swoboda, Esteban Jadresic, Paolo Mauro, and Andrew Berg. 2000. Exchange Rate Regimes In An Increasingly Integrated World Economy. International Monetary Fund: Washington D. C.

Quah, Chee-Heong. The Feasibility of East Asian monetary Union As An Optimum Currency Area. IJAPS Vol. 5, No. 2. 65 - 90. 2009 
Rosenberg, Richard. 2010. Does Microedit Really Help Poor People? Focus Note: Washington D. C.

Saxena, Sweta Chaman. Can South Asia Adopt a Common Currency. Journal of Economics Sin, Lew Yuen, and Ku A. T. L. Are Countries of Association of South East Asian Nations (ASEAN)

Candidates of Optimum Currency Area for Monetary Union? A Structural Var Approach. Review of Applied Economics, Vol 2, No. 2. 2006

Zhang, Zhaoyong, Kiyotaka Sato, and Michael McAleer. Is East Asia An Optimum Currency Area? 